\section{Revista Brasileira de Administração Científica}

Brazilian Journal of Scientific Administration

Abr a Jun $2019-$ v.10 - n.2

\title{
Governança corporativa: funções administrativas do conselho
}

A governança surge pela necessidade de auxiliar e orientar as companhias nos processos em conjuntura das mudanças globais, e compreendida como um conjunto de ações de incentivo e controle, para minimizar os custos e incentivar as boas práticas, com o objetivo de orientar e reger pelo bem-estar da empresa, sendo o Conselho de Administração seu principal pilar, e por função, zelar ao bom andamento dos processos corporativos, compartilhando informações e novas ideias com o executivo, gerência e operacional. No Brasil, a governança é recente, data dos anos 90 , com $80 \%$ das instituições em capital fechado, ao contrário das empresas de capital aberto, com negociações em Bolsa de Valores. Para uma boa adequação, faz-se necessário a análise de novos processos, ajustando-se aos novos critérios de mercado competitivo, e seguir o melhor caminho ao crescimento corporativo. A Comissão de Valores Mobiliários, órgão regulador, o Instituto Brasileiro de Governança Corporativa e a Organização para a Cooperação e Desenvolvimento Econômico, órgãos orientadores, auxiliam os conselhos em quais caminhos seguir e evitar conflitos legais. O conselho necessita estar seguro nas tomadas de decisões, assim como riscos envolvidos, prestigiando seus investidores e acionistas, não diferenciando os grupos acionários atuantes na companhia. Por se tratar de uma pesquisa qualitativa, procura explorar e documentar experiências ligadas às áreas administrativas, Bolsa de Valores, compliance, compartilhamento de informações, e pertinente ao contexto temos as Ofertas Públicas de Ações, que regem e controlam as aquisições de ações no mercado de capitais.

Palavras-chave: Governança; Código de Conduta; Boas Práticas; Auditoria; OPA.

\section{Corporate governance: board administrative functions}

Governance arises from the need to assist and guide companies in the processes of global change, understood as a set of incentive and control actions, to minimize costs and encourage good practices, aiming to guide and govern for the good. -being of the company, being the Board of Directors its main pillar, and by function, to ensure the smooth running of corporate processes, sharing information and new ideas with the executive, management and operational. In Brazil, governance is recent, dating from the 1990 s, with $80 \%$ of privately held institutions, as opposed to publicly traded companies, which are traded on the stock exchange. For a good fit, it is necessary to analyze new processes, adjusting to the new competitive market criteria, and follow the best path to corporate growth. The Securities Commission, the regulatory body, the Brazilian Institute of Corporate Governance and the Organization for Economic Co-operation and Development, guiding bodies, assist the councils in which paths to follow and avoid legal conflicts. The board needs to be safe in its decision-making, as well as the risks involved, honoring its investors and shareholders, not differentiating the active groups in the company. As this is a qualitative research, it seeks to explore and document experiences related to the administrative areas, the Stock Exchange, compliance, information sharing, and pertinent to the context we have the Public Offerings of Shares, which govern and control the acquisition of shares in the stock market capitals.

Keywords: Governance; Code of conduct; Good habits; Audit; OPA

Topic: Comunicação e Informação Organizacional

Reviewed anonymously in the process of blind peer.
Received: 09/04/2019

Approved: 12/06/2019
Celso Candido (iD

Centro Universitário Das Faculdades Metropolitanas Unidas, Brasil http://lattes.cnpq.br/6665374575535537

http://orcid.org/0000-0001-6846-0984

prof.celso@outlook.com
Referencing this:

CANDIDO, C.. Governança corporativa: funções administrativas do conselho. Revista Brasileira de Administração Científica, v.10, n.2, p.94-108, 2019. DOI: http://doi.org/10.6008/CBPC2179684X.2019.002.0007 


\section{INTRODUÇÃO}

Com o mercado cada vez mais globalizado, têm-se, também, mudanças profundas na economia, forçando a um novo modelo de como trabalhar os processos corporativos, antes apenas restrito à sua origem de uma economia local para internacional. Essas novas formas de trabalhar forçam os mercados a uma série de mudanças, novos conceitos econômicos e promovem uma competição cruel entre os segmentos da empresa.

Todas as mudanças possuem como objetivo auxiliar as companhias a se tornarem transparentes e apresentar melhores níveis de competividade no mercado em que atuam, imposta a partir do século XX, gerando a necessidade de aumentar e dinamizar a produção empresarial, assim como seus lucros, novas ideias, inovações e compartilhamento dos meios, disponibilizados pelos sistemas de informação e comunicação, impulsionados pela tecnologia, que explodiu nos anos 80 com o aparecimento de novas ferramentas de pesquisas, elevando a disseminação dos Sistemas de Informação. Esses novos conceitos obrigam as instituições a seguirem um ritmo de crescimento acelerado relacionados com as áreas de conhecimento no corporativo, contribuindo no surgimento de processos mais robustos e um melhor controle de suas aplicações tendo como base as novas regras, códigos de ética e padrões de comportamento.

A governança não possui como ideia principal apresentar conceitos milagrosos, mas auxiliar criações de mecanismos eficientes que contribuam para um crescimento uniforme, e facilite o monitoramento dos processos internos e externos. As áreas corporativas para continuarem competitivas necessitam de novas ideias e inovações, e que direcione os processos para padrões de comportamento que gerem crescimento, alinhe os conflitos entre acionistas e executivos, e melhore os processos, compliance e éticos das instituições, e que segundo Coelho (2007):

$\mathrm{Na}$ teoria econômica tradicional, a governança corporativa surge para procurar superar o chamado conflito de agência, presente a partir do fenômeno da separação entre a propriedade e a gestão empresarial. 0 principal, titular da propriedade, delega ao agente o poder de decisão sobre essa propriedade. A partir daí surgem os chamados conflitos de agência, pois os interesses daquele que administra a propriedade nem sempre estão alinhados com os de seu titular. Sob a perspectiva da teoria da agência, a preocupação maior é criar mecanismos eficientes (sistemas de monitoramento e incentivos) para garantir que o comportamento dos executivos esteja alinhado com o interesse dos acionistas.

Todo esse crescimento constante dos meios nas empresas, seja de pequeno, médio ou grande porte, necessitam de um melhor controle de seus valores e dos níveis de Governança Corporativa, capital aberto ou fechado, acompanhando e monitorando os investimentos em Bolsas de Valores, estas refletindo a situação do mercado brasileiro e mundial. Nesse sentido, Silva (2016) considera a governança corporativa como um sistema de aperfeiçoamento da gestão ao agregar valores ao administrativo e aos negócios empresa.

A governança corporativa não é um modismo, é um sistema aperfeiçoado de gestão, porque dele emana o comportamento da diretoria executiva de passar mais informações ao mercado como maneira de agregar valor ao negócio e também de estruturar a administração da empresa para que o valor dos acionistas seja aumentado, através do mercado de capitais. 
Com o crescente uso das tecnologias, surgem diversas facilidades, quanto à monitoração e controle das informações em tempo real. Seu início se deu com sistema simples de leitura dos dados, no início dos anos 50 até os primórdios dos anos 80, e a partir dos anos 90 vivencia-se um crescimento exponencial dessas tecnologias, com sistemas mais robustos e interfaces gráficas complexas, inicialmente implantadas por companhias renomadas como: a IBM, CISCO, Microsoft e outras.

Esse melhor controle em conjunto com a boas práticas de governança é destacado por Silva (2016) de como o avanço tecnológico foi determinante e impôs na evolução dos processos de governança um melhor controle sobre o mercado acionário, anos 50, sobre os primeiros conceitos de governança, marcando o início de um novo conjunto de ideias e inovações. Nessa época, via-se muitos conselhos inoperantes, e devido ao grande número de empresas familiares, a ideia de família ainda permanecia forte, com uma atuação direta do acionista controlador nas movimentações das ações.

Dentro de um contexto de mudanças tecnológicas constantes e aceleradas, com reflexos nas relações político-econômicas e sociais, são necessários o crescimento e a modernização da indústria e da prestação de serviços, com base não apenas na inovação, incorporação de novas tecnologias e capital mas também na capacidade de gerenciamento das organizações que devem desenvolver a competição de forma objetiva e em crescentes níveis de qualidade e produtividade.

Nas palavras de Silva (2016), a Governança Corporativa traz um conjunto de processos, costumes, políticas, leis e instituições usados na administração da companhia, com o constante compartilhamento das informações entre seus acionistas (stakeholders), executivo e o Conselho de Administração, na elaboração dessas informações, na análise e na implementação de diretrizes e suas orientações, necessários para que a companhia possa alcançar seus objetivos perante o novo mercado. Por serem sistemas complexos, requerem constante avaliação, prevenção e análise dos riscos, de forma a minimizar possíveis perdas, manter as metas e as regras reguladoras, que auxiliam ao bom andamento dos processos entre as partes envolvidas.

Na hierarquia corporativa, o Conselho de Administração ou Boards, considerado como um dos principais órgãos colegiados da companhia, sendo responsável pelo processo de decisão e direcionamento estratégico, possui por função assegurar que os negócios se perpetuem através de resultados satisfatórios durante sua existência, considerado o elo entre a propriedade e a gestão, orientando e supervisionando a relação com as partes interessadas.

Segundo Camargo (2016), a criação de um Conselho de Administração teve seu ponto de partida na década de 1980, nos Estados Unidos e na Inglaterra. A intenção era de alinhar os interesses dos acionistas (stakeholders) com a gestão executiva, em companhias de capital aberto, instituições financeiras e seguradoras, assim seriam obrigadas por lei a ter conselhos administrativos, atuando na falta de transparência administrativa das companhias e defendendo um controle mais eficaz de seus acionistas na geração de valores e riquezas.

Conforme Silva (2016), o Instituto Brasileiro de Governança Corporativa orienta que a origem da boa governança teve seu início na primeira metade dos anos 90. Com o movimento iniciado nos Estados Unidos, os acionistas se conscientizaram de que novas regras precisavam ser criadas para se protegerem dos abusos impostos pela Diretoria Executiva ou Chief Executive Officer das empresas, pela inércia de conselhos 
inoperantes e omissões de autoridades externas. Com a implantação da governança dentro dos Conselhos Administrativos contribuiu para um desenvolvimento econômico sustentável, auxilia nas melhorias de desempenho, acelera seus resultados e facilita o acesso aos recursos de fontes externas.

\section{METODOLOGIA}

Ponderar as melhores práticas usadas em um Conselho de Administração, e como auxiliam nas decisões corporativas. Fachin (2003) compreende que "[...] a exposição dos conceitos de ciência põe em relevo a forma pela qual a pesquisa cientifica dá valor à evidência dos fatos ou objetivos, mostrando como cada área da ciência geralmente se inicia com o dado oriundos da observação e da verificação, seguindo parâmetros da metodologia científica".

Segundo Oliveira (2002), o desenvolvimento adequado de uma pesquisa científica, se faz necessário um planejamento cuidadoso e investigativo de acordo com as normas da metodologia científica, tanto referente à forma quanto a que ao conteúdo. Salomon (1990) entende que a metodologia é uma condição necessária, mas não suficiente, para a realização científica, e apesar de não haver produção do conhecimento científico sem método, a sua aplicação por si não produz conhecimento, quando surge um problema, para o qual se procura a solução adequada de natureza científica.

O modelo de pesquisa é qualitativo de caráter exploratório, com pesquisas bibliográficas, analisando, comparando e concluindo os comentários apresentados por seus autores, na forma de: tabelas, quadros ou imagens. Nesse sentido este artigo procura ponderar em resumo as melhores práticas usadas em um Conselho de Administração e como auxiliam nas tomadas de decisões nos conselhos administrativos.

\section{DISCUSSÃO TEÓRICA}

\section{Conselho de Administração: formas de atuação}

Segundo Kashio (2018), a atuação do Conselho de Administração é um tema recorrente em estudos da Governança Corporativa considerados polêmicos, ao se comentar sobre atribuições e deveres. Um breve relato do IBGC ressalta que a formação do conselho assume um papel de grande importância dentro de uma companhia, uma vez que suas negociações poderão ter um saldo negativo ou positivo.

[...] nem sempre as empresas contam com conselheiros qualificados para o cargo e que exerçam, de fato, sua função legal. Essa deficiência tem sido a raiz de grande parte dos problemas e fracassos nas empresas, na maioria das vezes decorrentes de abusos de poder (do acionista controlador sobre minoritários, da diretoria sobre o acionista e dos administradores sobre terceiros), erros estratégicos (decorrentes de muito poder concentrado numa só pessoa, normalmente o executivo principal), ou fraudes (uso de informação privilegiada em benefício próprio, atuação em conflitos de interesses).

Silva (2016) reforça que a gestão estratégica é de grande relevância para a companhia, centralizando suas atividades nos focos estratégicos que usam a governança corporativa a partir de seus princípios básicos, transparência nas divulgações e com informações que demonstram a saúde financeira da companhia. Dessa forma o conselho necessita estar alinhado com o executivo, auxiliando e discutindo as decisões de forma correta, visando o crescimento financeiro em acordo com os órgãos que atuam na regulação legal e auxiliam 
em seus padrões comportamentais e éticos. Não estar em sincronia com esses padrões, significa colocar em risco o mercado em que a empresa atua, e por consequência um baixo crescimento e lentidão dos processos.

O Art. 142 da Lei 6.404 (BRASIL, 1976) esclarece quanto a competência do Conselho de Administração, tendo como principais missões: zelar e proteger o patrimônio da companhia maximizando o retorno do investimento dos acionistas, agregando valor ao empreendimento, elaborando estratégias de mercado em acordo com as diretrizes impostas pelo executivo, compartilhar as informações com a sociedade, estabelecer regras de conduta (códigos de ética), deveres na hierarquia da companhia, zelar por seus valores, crenças e propósitos dos acionistas em suas atividades.

O Art. 141 da Lei 6.404 (BRASIL, 1976), complementa que as atividades de competência do conselho de administração devem estar normatizadas em um regimento interno, tornando claras suas responsabilidades e atribuições, prevendo situações de conflito com a diretoria executiva e demais, na intermediação entre os acionistas, auxiliando nos processos de auditoria interna e estimulando a criação do código de ética da companhia.

O envolvimento em assuntos de nível operacional da diretoria executiva é de responsabilidades de seus diretores, não sendo aconselhável ao conselho de administração, que possui como principal atribuição o de cuidar dos processos estratégicos. Caso seja necessária a participação do Conselho nos processos operacionais, deverá haver um equilíbrio decisório entre os atos de deliberação e de gestão. Nalder (2004) sugere cinco modelos de conselho de administração quanto à sua construção e à definição de suas funções:

[...] (a) Conselho Passivo (tradicional): suas atividades e sua participação são mínimas e definidas pelo presidente executivo. Sua finalidade é ratificar as decisões da diretoria; (b) Conselho Certificador: com atribuição principal para os processos de supervisão da direção executiva, sendo o avalista da gestão perante os acionistas; (c) Conselho Envolvido: o conselho e a direção executiva atuam como parceiros e o conselho apresenta suas ideias e apoio para a tomada de decisões relevantes; (d) Conselho Interventor (Comum): atua em crises financeiras e/ou escândalos, por função, deverá intervir constantemente, para uma pré-análise dos processos de gestão; (e) Conselho Operador: a diretoria executiva programa decisões que são tomadas no conselho, envolvendo diversas áreas funcionais e de negócios da companhia, que se encontram em fase de ajustamento organizacional e aprendizado na área de negócios em que atuam.

\section{Governança Corporativa}

Existem inúmeras definições para Governança Corporativa que procuram orientar e expor as melhores práticas para que o Conselho possa trabalhar, planejar e compartilhar as informações entre as partes interessadas, como o Sistema de Relações - Instituto Brasileiro de Governança Corporativa pelo Código das Melhores Práticas de Governança Corporativa e o Guardiã de Direitos - Organização para a Cooperação e Desenvolvimento Econômico pelos Princípios de Governança Corporativa. "A governança corporativa é um novo nome para o sistema de relacionamento entre acionistas, auditores independentes e executivos da empresa, liderado pelo Conselho de Administração" (LODI, 2000).

A BLB (2017), BLB Brasil Auditores e Consultores, empresa ligada aos ramos de auditorias e consultorias, o Conselho de Administração é constituído como um órgão próprio das Sociedades Anônimas, também muito referenciadas como companhias. Hoje qualquer sociedade pode deliberar por instituir o 
Conselho de Administração e adotar as boas práticas de Governança Corporativa, independentemente do tipo societário em que esteja enquadrada, como: sociedade anônima, limitada, dentre outros, e independentemente de seu porte. O intuito principal deste órgão é o de mitigar, suavizar, conflitos entre os administradores da empresa e seus sócios.

O Conselho de Administração é considerado o colegiado encarregado do processo de decisão de uma companhia, direcionando estrategicamente os processos decisórios e ser o elo entre os sócios e a diretoria executiva, necessita orientar e supervisionar continuamente a gestão entre todas as partes interessadas, valorizando-a e buscando o equilíbrio no interesse dos sócios e demais integrantes da companhia. Rodrigues (2012) entende que os conselheiros eleitos pelos acionistas têm o papel de proteger e valorizar o patrimônio da companhia, maximizando investimentos.

[...] têm um papel muito distinto dos executivos. Sua missão inclui acompanhar e estimular um melhor desempenho da gestão executiva, aprovar e coordenar a execução das estratégias de negócio, gerenciar riscos de alto nível, zelar pelos princípios, valores e padrões éticos da organização e por sua aplicação nas decisões da empresa [...]. Em síntese, sua missão é proteger e valorizar o patrimônio e maximizar o retorno do investimento com vistas à perenizarão do negócio. Para que funcione bem, o CA tem que ter a máxima independência em relação à gestão executiva. Assim, deve promover mudanças quando os resultados dos negócios indicarem essa necessidade, incluindo até a substituição do executivo principal [...].

O Conselho Administrativo precisa zelar pelo patrimônio dos sócios da companhia, que o elegeu, sendo os guardiões que mantêm o equilíbrio entre sócios e parcerias com companhias concorrentes e atuação no mesmo mercado de produtos e serviços. Segundo Rodrigues (2012), um Conselho Administrativo "melhora muito a qualidade das decisões estratégicas e contribui para mitigar riscos, entre outros benefícios".

As colocações de Rodrigues (2012) são complementadas pela BLB (2017) em que o Conselho de Administração poderá, inclusive, somar para a adoção das boas práticas da Governança Corporativa, "criando ou adequando este órgão para consolidar os negócios no mercado, com diferencial competitivo sustentável e estratégico" Rodrigues (2012).

\section{Princípios e regras}

Do mesmo modo, ao se praticar a boa governança, os conselhos necessitam atingir níveis próximos dos seus ideais, que demonstrem equilíbrio com os padrões de comportamento (compliance) as regras estabelecidas pela governança no bom andamento dos processos, sendo necessário que as áreas e os seguimentos envolvidos estejam em acordo com as boas práticas, estabelecidas pelo Instituto Brasileiro de Governança Corporativa, pela Comissão de Valores Imobiliários e pela Organização para a Cooperação e Desenvolvimento Econômico.

Apesar de os órgãos reguladores serem atuantes no que tangem a governança, a definição de um conjunto dos princípios de regras asseguram um melhor controle nos negócios e nas informações compartilhadas, na teoria a ideia aparenta simples, na prática, sua aplicação é complexa no âmbito empresarial, onde o consenso depende de diversas decisões das áreas envolvidas, e caso haja o surgimento 
conflitos de interesses, faz-se necessário que o assunto da pauta seja discutido e como ideias alternativas iram contribuir para amenizar esses conflitos.

Para uma análise de como os conjunto de princípios de uma companhia procura englobar as suas áreas atuantes entre os diversos níveis, por exemplo, pode-se comparar duas instituições de nomes $\mathrm{X}$ e $\mathrm{Y}$, que para efeito de análise, são empresas distintas, e que não possuem um padrão único de trabalho, mas que atuam no mesmo nicho de mercado e dependem de um bom trabalho entre partes.

Se não for definido um conjunto de princípios e regras, o segmento da companhia X poderá não se aplicar necessariamente ao segmento da companhia $\mathrm{Y}$, por não haver um boa compreensão dos processos de cada empresa, moral da história, as decisões nem sempre se aplicam a todos, mas necessárias quanto ao compartilhamento das informações e o não uso das regras de boas práticas poderá causar divergências, conflitos, com relação a comunicação entre as companhias, poderá levar a falhas no entendimento de como atuar e uma quebra dos conceitos a serem usados. Nesse sentido, o Código das Melhores Práticas de Governança Corporativa define que

A Governança Corporativa é o sistema pelo qual as organizações são dirigidas, monitoradas e incentivadas, envolvendo os relacionamentos entre proprietários, Conselho de Administração, Diretoria e órgãos de controle. As boas práticas de Governança Corporativa convertem princípios em recomendações objetivas, alinhando interesses com a finalidade de preservar e otimizar o valor da organização, facilitando seu acesso a recursos e contribuindo para sua longevidade.

Ao relacionar os conceitos das boas práticas, não importando o seguimento escolhido pela companhia, diversas dificuldades e dúvidas surgem ao trabalhar os princípios e as regras de governança, empresa familiares ou sociedade anônima. Nesse sentido, para auxiliar, o IBCG (2009) divide a governança corporativa em 04 princípios básicos.

[...] (a) Transparência - Visa disponibilizar entre as partes interessadas a disseminação das informações de interesse mútuo e não apenas as descritas pelas leis ou regulamentos. (b) Equidade - $O$ justo tratamento entre os sócios e os stakeholders. (c) Prestação de Contas Todos os agentes de governança precisam estar acostumados com as prestações de contas sobre suas diversas atuações e assumir suas consequências caso seja comprovada omissões. (d) Responsabilidade Corporativa - Os agentes de governança devem zelar pela sustentabilidade das organizações incorporando considerações de ordem social e ambiental na definição dos negócios e operações.

Outro ponto, não menos importante, é a análise das procedências da comunicação usada pelo segmento escolhido, por motivos éticos e de compliance, como a necessidade de conhecer foi gerada e como a informação poderia ser trabalhada, para que gere novos conceitos, principalmente se forem inovadores, podendo auxiliar no desenvolvimento de melhores processos, confiáveis, e com um maior campo de utilização. Se aplicado de forma correta, conforme padrões de comportamento, ética e atos reguladores, o avanço tecnológico e corporativo serão consequências, e com a orientação de um sistema contínuo de auditoria nas informações.

Em relação às regras relacionadas, a governança, precisa ser usada no auxílio das diretrizes da companhia e que contribua de forma precisa e correta, sempre que necessário, em acordo com o Conselho de Administração e no auxílio das decisões de seus sócios e stakeholder. Para melhor visualizar os processos 
descritos, a figura 1, por exemplo, demonstra o fluxo a percorrer, partindo da informação disponibilizada até a etapa de auditoria, e retornando ao início para um novo ciclo de análises.

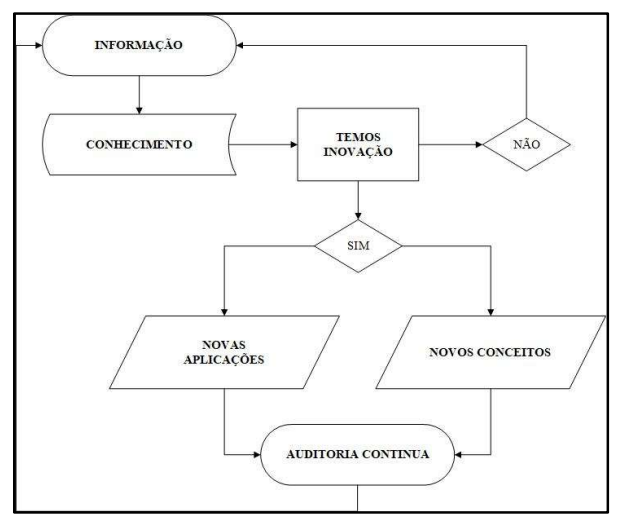

Figura 1: Auditoria Contínua.

\section{Código de conduta}

O IBGC (2016) define como ética e conflito de interesses que "A companhia deve ter um código de conduta, que promova seus valores e princípios éticos e reflita a identidade e cultura organizacionais, e um canal de denúncias para acolher críticas, dúvidas, reclamações e denúncias" (IBGC, 2016). No Brasil, tem-se a impressão de um desencontro das informações do Instituto Brasileiro de Governança Corporativa com relação as condutas dos conselhos, ocasionando conflitos de interesses e quebras de conceitos éticos. Não significa que não exista Instituições que trabalham corretamente, temos ótimos exemplos, como o Grupo Marisa e o Grupo Telefônica, reconhecidas com empresas atuantes e com uma boa governança, mas para se obter bons níveis, faz-se necessário que as regras sejam seguidas, com uma contínua auditoria das informações e dos processos.

Uma forma muito comum de controle, as contratações de auditorias externas, sem a interferência da auditoria interna, capital fechado ou aberto, que por não estarem vinculadas aos processos internos não possuem acordos entre partes para benefícios próprios. O Instituto Brasileiro de Governança Corporativa orienta e recomenda algumas práticas de conduta, relacionados pelo Código Brasileiro de Governança Corporativa das Companhias Abertas (IBGC, 2016).

A companhia deve ter um comitê de conduta, dotado de independência e autonomia e vinculado diretamente ao conselho de administração, encarregado de implementação, disseminação, treinamento, revisão e atualização do código de conduta e do canal de denúncias, bem como da condução de apurações e propositura de medidas corretivas relativas às infrações ao código de conduta.

O Brasil iniciou os princípios da Governança Corporativa a partir da década de 90, com a fundação em 1995 do Instituto Brasileiro de Conselheiros de Administração (IBCA), atualmente, com o nome de Instituto Brasileiro de Governança Corporativa (IBGC), com a missão de orientar os conselhos administrativos relacionado a suas condutas, padrões de comportamento, ética e compartilhamento das informações entre seus acionistas, conselheiros, executivo e operacional e que conforme Deutsch (2014),

Fica exposto, então, o desconhecimento do país na questão do ativismo societário na década de 90 . [...] a governança corporativa não é um mero comportamento ao qual estão sujeitos os administradores das companhias que optarem em aumentar a rigidez de seu 
quadro societário, criando mecanismos que não permitam, a estes administradores ou ao próprio acionista controlador, a obtenção de vantagens de seu interesse em detrimento da própria companhia, a governança corporativa vai além, ela determinas as regras de funcionamento das aprovações societárias, ela coíbe determinados atos sem o voto afirmativo dos minoritários, obriga determinada companhia a emitir tão somente ações ordinárias, sendo vedadas as ações preferenciais, que não exercem controle sobre a companhia, mas são tão somente um meio de se obter vantagem econômica (com exceção às hipóteses legais), busca mecanismos que dotem os minoritários de voz, e, principalmente, busca manter uma relação harmônica entre os interesses de todos os acionistas, alinhando suas condutas para melhor desempenho da companhia.

Como órgão regulador, a Comissão de Valores Imobiliários, criada em 07 de dezembro de 1976 pela Lei $6.385 / 76$, tem o objetivo de fiscalizar, normatizar, disciplinar e desenvolver o mercado de valores mobiliários no Brasil, e conforme Art. 1 da Portaria 327, sendo considerada '[...] uma entidade autárquica vinculada ao Ministério da Fazenda, dotada de personalidade jurídica e patrimônio próprio, com as finalidades previstas na Lei no 6.385, de 07 de dezembro de 1976 e na Lei no 6.404, de 15 de dezembro de 1976, no presente Regimento Interno, e nas demais disposições legais e complementares aplicáveis'.

\section{Estrutura dos Conselhos: Fechada e Aberta}

Tanto uma empresa familiar (capital fechado), quanto as de sociedade anônima (capital aberto) possuem conselhos, sendo que nas companhias anônimas são mais ativos e com poder de decisão. Silva (2016) define uma empresa familiar como "[...] a empresa que tem como principais acionistas uma ou mais famílias que detêm o comando da gestão, [...] é caracterizada por trazer em sua cultura os elementos que envolvem as relações familiares". Em relação à sociedade anônima, Silva (2016) define como uma "[...] empresa que tem o capital dividido em ações, com a responsabilidade de seus acionistas limitada proporcionalmente ao valor de emissão das ações subscritas ou adquiridas".

Além dos entendimentos apresentados por Silva (2016), temos a existência de diferenças entre os conselhos de uma companhia familiar e sociedade anônima. Segundo Prado (2016), com relação às anônimas, temos um conselho administrativo, atuante e com tomadas de decisões; nas familiares, temos um conselho consultivo ou familiar, não atuante, se limitando a foro de trocas de ideias e aconselhamentos.

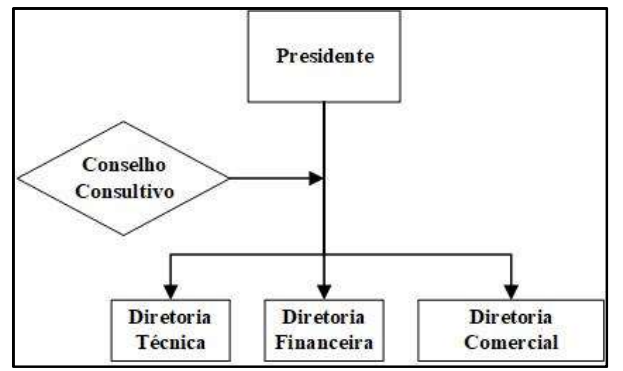

Figura 2: Estrutura de Conselho: Empresa Familiar. Fonte: Prado (2015).

Quando feita graficamente uma análise da estrutura de uma empresa familiar, figura 2, vê-se de forma clara a existência do Conselho Consultivo, e suas limitações, não sendo ligado diretamente as obrigações administrativas da companhia por não possuir poder de decisão. Sua principal função, entre outras, é assessorar os sócios em relação as táticas e estratégias de gestão, que segundo Prado (2015) 
O conselho consultivo é um órgão não obrigatório por lei, portanto optativo, criado pelos sócios do negócio por sua livre-iniciativa, cujo principal objetivo é assessorar, sugerir e recomendar, aos sócios gestores, ações ligadas à gestão tática e estratégica dos negócios. O conselho consultivo não delibera nem decide.

Em comparação da estrutura da companhia de capital fechado, figura 2, abaixo do Presidente temse o Conselho Consultivo, parecido até certo ponto, com o Conselho de Administração, figura 3, empresas de capital aberto, com poder de decisão e responsabilidades legais, onde a decisão final cabe aos acionistas controladores, sendo um modelo de estruturação organizacional bem vista por seus stakeholders.

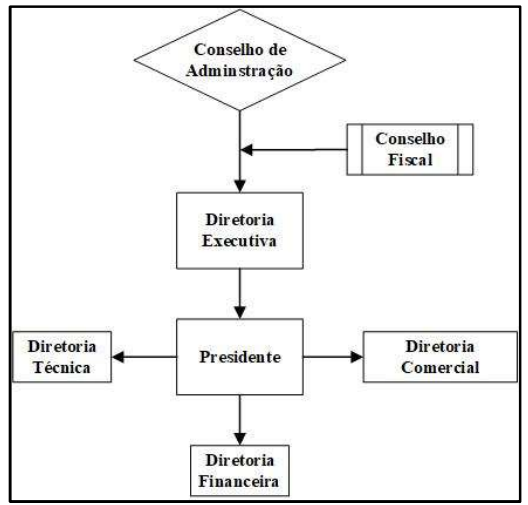

Figura 3: Estrutura de um Conselho Administrativo. Fonte: Prado (2015).

Com forte influência dos conselhos nas instituições de capital aberto, com a finalidade de obter um melhor controle de seus processos, também se verifica um aumento dos Conselhos Administrativos atuando em empresas familiares, com a intenção de expandir o mercado, por intermédio das Consultorias independentes, e melhor gerenciar seus processos, mantendo o capital adquirido, ou preparar esse capital para uma abertura de mercado de fechado para aberto. O Código das Melhores Práticas de Governança Corporativa (IBGC, 2007) esclarece que, independentemente de sua forma societária e de ser companhia aberta ou fechada, toda sociedade deve ter um Conselho de Administração eleito pelos sócios, sem perder de vista todas as demais partes interessadas (stakeholders), o objeto social e a sustentabilidade da sociedade no longo prazo.

Os conselhos, familiar ou sociedade anônima, se faz necessário sempre que possível analisar os interesses da companhia e decidir os pontos comuns com os interesses da sociedade, independentemente da parte que os indicou ou elegeu, Segundo o Código das Melhores Práticas de Governança Corporativa: "A missão do Conselho de Administração é proteger e valorizar o patrimônio, bem como maximizar o retorno do investimento" (IBGC, 2007).

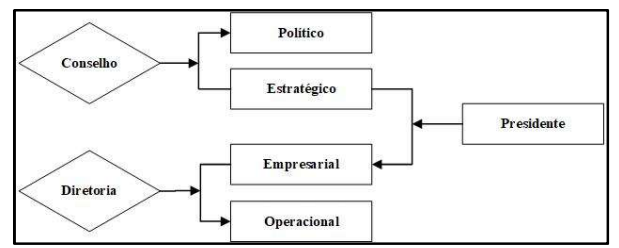

Figura 4: O conselho de administração e a gestão. Fonte: Silva (2016).

O grande objetivo é buscarmos maior confiança, ética e alinhamento estratégico entre as visões de longo prazo (CA) e de curto prazo (DE). A finalidade é uma maior entre a função de controle da governança e a gestão dos negócios, almejando a criação/geração de valor 
para a sociedade de forma perene e com sustentabilidade (econômica, social e ambiental, quando aplicável).

Segundo Silva (2016), ao se tratar de uma companhia de capital aberto, a confiabilidade da gestão e o nível de delegação do conselho, necessitam ser atuantes em relação as estratégias de mercado, quais seriam as prioridades, como as informações foram obtidas, por representar diretamente os acionistas, com as quais o diretor-presidente e a diretoria executiva trabalham, condizentes com o Art. 142 da Lei 6.404 (BRASIL, 1976), representado pela figura 4.

\section{Oferta pública de aquisições a priori e a posteriori}

A Oferta Pública de Aquisições (OPA) rege e controla as ações na Bolsa de Valores, para melhor compreensão, seriam a compra de valores imobiliários que poderiam ou não inserir sobre o controle de uma companhia aberta ou redigir como poderá se tornar uma instituição de capital fechado. Prado (2005) entende que duas são atualmente as modalidades de Oferta Pública de Aquisições previstas e controladas pela Lei 6.404, de 15 de dezembro de 1976: a) Oferta Pública de Aquisições voluntária de tomada hostil de controle societário (Art. 257 e seguintes); e b) Oferta Pública de Aquisições obrigatória decorrente da alienação de controle da companhia aberta (Art. 254-A), e que no Brasil encontram-se reguladas pela Instrução CVM 361, de 5 de março de 2002, conforme o Art. 02, pág. 1- 3.

Prado (2005) comenta que, ao se votar no tempo, tem-se a impressão que o controle estabelecido pelas leis acionárias não é antiga, data dos anos 60, por exemplo, podemos citar os Estados Unidos, por não existir na época uma norma legal ou algum regulamento que proibia determinadas atitudes por parte dos acionistas nas aquisições de ações, podendo ou não levar ao controle acionário da companhia de capital aberto. Com relação às empresas de capital fechado, por não possuírem um controle acionário, as decisões de seus dirigentes chegavam a serem hostis e seguiam uma hierarquia do fundador (dono da companhia) para com seus familiares, raramente se viam acionistas nesse modelo de companhia que não partilhavam as regras familiares e direciona que

orienta que Oferta Pública de Ações Obrigatórias, denominada a posteriori, Art. 254-A (LSA, 1976), demonstram três mecanismos principais: (a) a oferta pública hostil de tomada de controle; (b) a escalada em Bolsa de Valores; (c) a cessão privada de controle. Dessa forma [...] o mercado de controle societário tem como função jurídica primordial possibilitar uma melhor administração social das companhias abertas. [...] tendo em vista a importância jurídico-econômica deste mercado de controle societário [...] paralelamente aos mercados acionários primário e secundário.

Regulado pelo Art. 257 e seguintes da Lei 6.404 (BRASIL, 1976), tem-se a Oferta Pública de Ações a priori, denominada também de Oferta Pública de Ações voluntárias de tomada hostil, criada em virtude da necessidade de contratação direta com o(s) efetivo(s) controlador(es) para se atingir os seus objetivos de mercado e até mesmo se prevalecendo de apelo público para adquirir o controle acionário de uma companhia na qual se tenha interesse e segundo Prado (2005),

Seu objetivo primordial é melhorar as condições de desenvolvimento do mercado de controle societário, proteger os investidores de ofertas inidôneas, proporcionando-lhes um maior acesso às informações referentes à operação e garantindo que todos os acionistas 
minoritários da companhia recebem tratamento igualitário na alienação das ações de sua propriedade.

PRADO (2005) acrescenta que quando tem-se uma cessão de controle, considera-se como uma operação privada decorrente de uma prévia negociação, e desde que se obtenha um acordo entre as partes, dando plenos poderes para quem possui o controle da organização, esse modelo de cessão permite uma maior atuação no controle das movimentações financeiras da companhia, elegendo e fixando o detentor do controle acionário da organização, mas possui como principal desvantagem o seu custo operacional, com o prévio pagamento de um prêmio geralmente solicitado pelo alienante, sendo a forma mais usual pela qual um terceiro alheio ao controle societário poderá adquiri-lo.

Tudo isso conforme a Art. 254-A da Lei 6.404 (LSA, 1976), que prevê e regula a Oferta Pública de Ações a posteriori. No Brasil, a Oferta Pública de Ações usada é a posteriori, ou voluntária, descrita pelo art. 254-A da Lei 6.404 (LSA, 1976). Sua regulação se dá pela Instrução 361 (CVM, 2002), que segundo PRADO (2005)

[...] se trata de mecanismo de aquisição de controle societário que consiste na aquisição progressiva, em Bolsa de Valores e em contratações privadas com acionistas minoritários, de participação acionárias votantes de emissão da companhia aberta cujo controle se pretende adquirir, possuindo uma série de desvantagem, tanto para o ofertante quanto para os acionistas minoritários.

\section{Como realizar a opa para o fechamento de capital}

A Instrução 358 (CVM, 2002) orienta os primeiros passos para a realização da Oferta Pública de Ações, com a publicação do Ato ou Fato Relevante sobre a realização da oferta, seguido do um pedido de fechamento do capital e devendo ser protocolado em um prazo de até 30 dias junto à Comissão de Valores Imobiliários, que decidirá se a autorização será concedida ou não dentro de um novo prazo de 60 dias, onde a Comissão de Valores Imobiliários poderá exigir algumas mudanças na Oferta Pública de Ações para que seja aprovada.

Uma vez que o registro na Comissão de Valores Imobiliários seja obtido, Instrução 358 (CVM, 2002), a Oferta Pública de Ações será divulgada por meio de edital em jornais de grande circulação com prazo de 10 dias. Ao ser publicado, a Oferta Pública de Ações poderá se realizar dentro num prazo mínimo de 30 dias e máximo de 45 dias em leilão na Bolsa de Valores, sendo necessário que no edital esteja definida a data de realização do leilão, cabendo ao investidor credenciar, até a véspera, uma corretora para representá-lo, seja para concordar com o fechamento do capital ou discordar.

Com a ocorrência de $10 \%$ ou mais dos acionistas que não concordem com o valor proposto na Oferta Pública de Ações, poderão em até 15 dias depois da publicação do edital se organizarem e convocar uma nova assembleia, na qual eles deverão defender a falha na metodologia do laudo de avaliação para que o leilão seja adiado e uma nova avaliação seja feita por outra companhia.

Paiva (2014) acrescenta que todas as Ofertas Públicas de Ações, voluntárias ou obrigatórias, hostis, necessitam ser intermediadas por sociedade corretora ou distribuidora de valores mobiliários ou por instituição financeira, desde que possua uma carteira de investimentos. Nos termos da Instrução 361 (CVM, 
2002), a instituição intermediária, além de assegurar que as informações prestadas pelo ofertante sejam verdadeiras e corretas, caso contrário, responderam pela omissão de informações nessa obrigação, necessita que seja garantido a liquidez financeira da Oferta Pública de Ações, e complementa quanto a avaliação da companhia como um objeto que

[...] a contratação de laudo é obrigatória sempre que a OPA for formulada pela própria companhia, pelo acionista controlador ou pessoa a ele vinculada, excetuado expressamente o caso de alienação de controle, onde o valor da OPA é estabelecido pelo valor da negociação na qual o controle foi alienado. Referido laudo poderá ser elaborado pela instituição intermediária, sociedade corretora ou distribuidora de títulos ou valores mobiliários ou instituição financeira com carteira de investimentos que possuam área especializada e devidamente equipada e que tiverem experiência comprovada na avaliação de companhias abertas, bem como por empresa especializada, também com experiência comprovada na avaliação de companhias abertas. No caso de oferta que envolva permuta, logicamente a Instrução 361 determina que também deverá ser apresentado laudo de avaliação da companhia cujos valores mobiliários estejam sendo entregues em permuta, devendo-se utilizar o mesmo critério para ambas as companhias ou justificar-se a adoção de critérios distintos.

Carvalhosa (2009) e Paiva (2014) entendem que: “o papel da instituição financeira não se resume à intermediação; trata-se de parte integrante do negócio, sendo co-obrigada e co-ofertante". Segundo Prado (2005), a importância atribuída a regulação das Ofertas Públicas de Ações a priori e/ou a posteriori, por terem sido incorporadas pela quase totalidade das legislação que versam sobre o direito societário e mercado de capitais, como os dois principais mecanismo de regulação em resposta à discussão entre o princípio do livre mercado de tomadas de controle societário e o princípio do tratamento igualitário aos acionistas minoritários, garantindo que todos da companhia recebam tratamento igualitário na alienação das ações de propriedade.

\section{CONSIDERAÇÕES FINAIS}

Após análises na visão de uma empresa familiar ou aberta, conclui-se que temos formas distintas de atuar no mercado de capitais no âmbito da governança, sendo os conceitos e as regras, os pontos de partida para o crescimento, aprimoramento das formas de trabalho, comunicação dos processos e o compartilhamento das informações entre acionistas e stakeholders, com a maior incidência dos índices de governança nas de capital aberto.

Em relação ao mercado de ações, essencial em uma sociedade anônima, e menos expressiva nas empresas familiares, as tomadas de decisões poderão seguir ou não na contramão, podendo ocasionar interversões pela Comissão de Valores Mobiliários e como consequência, queda dos valores acionários. Para evitar esses contratempos, as instituições precisam seguir uma linha de crescimento que esteja coerente com as regras do mercado de capitais e os conceitos de governança.

O Brasil possui aproximadamente $80 \%$ de suas empresas no modelo familiar, com o poder da organização dividido entre os familiares e suas gerações, passando de pai para filho, por possuírem uma governança simplificada ou ausente, não usam um conselho de administração ativo, mas um conselho consultivo, menos atuante, comuns nessas organizações, com uma atuação discreta nas comercializações de suas ações. 
Dessa forma, o empreendimento perpetua entre gerações, levando o processo de amadurecimento das ideias e consensos no decorrer dos anos. Muitas instituições familiares, ao ocorrer mudanças na diretoria executiva, devido a diversos fatores como o crescimento e os padrões de comportamento, tem-se a contratação de terceiros, consultorias de conselhos administrativos, por possuírem um conhecimento organizacional melhor e mais adequado do mercado, por consequência temos um melhor gerenciamento de suas atividades e um futuro egresso para uma companhia de capital aberto.

As sociedades anônimas, ao contrário das familiares, possuem um conselho ativo, assumem riscos e necessitam estarem em acordo com a regulação legal, as tomadas de decisões e as responsabilidades impostas pelo mercado de capital. A comercializações de suas ações são através de outros investidores, compra e venda, sendo o presidente executivo, cargo mais elevado, possuem um melhor controle fiscal, sendo mais competitivas e preparadas, desenvolvendo novas ideias, inovando, compartilhando informações e controlando processos, orientadas pelas regras e conceitos da governança. Em análise aos dois modelos, familiar ou aberta, para ser competitivo e atuante, as decisões precisam seguir os padrões estabelecidos pela governança e órgãos que regulam o mercado de capitais, por definirem os princípios e as formas de conduta.

Com relação as Ofertas Públicas de Ações, a priori e a posteriori, sua implementação é necessária para que se tenha um controle do fluxo de ações na Bolsa de Valores, e ser correto nas informações apresentadas em negociações entre os acionistas majoritários e minoritários. As regras que regulam o mercado das Oferta Pública de Ações direcionam as decisões, conforme os Arts. 254 e 257-A da Lei 6.404 (LSA, 1976) e regulada pela Instrução 361 (CVM, 2002), através da Comissão de Valores Mobiliários como principal forma de controle e no cumprimento dessas regras e como forma de controle exclusivo das empresas de capital aberto, tendo pouca influência nas de capital fechado.

O controle através de regras e normas que moldam o mercado, datam da década de 1950, e devido as dificuldades de implementar novas ideias serem lentas, a Governança Corporativa somente começou a criar força na década de 1990 com o fortalecimento dos Conselhos Administrativos, os acionistas perceberam a necessidade de utilizar regras que assegurassem a proteção de seus capitais dos abusos impostos pelas diretorias executivas, da inoperância dos conselhos de administração e das omissões das auditorias externas, o principal objetivo seria obter empresas melhores preparadas, com responsabilidades social e comercial, seguindo regras, compartilhando as informações e em constante atualização com a realidade do mercado que atuam.

Pode-se dizer que as instituições que não operam com transparência não sobrevivem por muito tempo, ou são mortas pelas próprias regras ou pelo mercado que atuam. Até que apareça um novo conceito de regras e responsabilidades a Governança Corporativa estará atuante, talvez com outros conceitos, contribuindo cada vez mais para que as companhias sejam sustentáveis, transparentes, sociais e condizentes com o que o mercado está solicitando.

\section{REFERÊNCIAS}

BRASIL. Lei n.6.404 de 15 de dezembro de 1976. Lei das

Sociedades Anônimas. Brasília: DOU, 1976. 
BRASIL. Portaria n.327 de 11 de julho de 1977. Regimento interno da Comissão de Valores Imobiliários. Brasília: DOU, 1977.

CAMARGO, R. F.. Conselho de Administração: saiba como sua empresa pode se beneficiar com um bom Conselho Administrativo. Blumenau: 2016.

CARVALHOSA, M.. Comentários à lei de sociedades anônimas. 9 ed. São Paulo: Saraiva, 2009.

CERVO, A. L.; BERVIAN, P. A.; SILVA, R.. Metodologia científica. São Paulo: Pearson Prentice Hall, 2007.

COELHO, F. U.. Curso de Direito Comercial: Direito de Empresa. São Paulo: Saraiva, 2010.

COELHO, M. A.. Governança Corporativa. Curitiba: UFPR, 2007.

CVM. Comissão de Valores Imobiliários. Instrução CVM 358 de 3 de janeiro de 2002. Dispõe sobre a divulgação e uso de informações sobre ato ou fato relevante relativo às companhias abertas, disciplina a divulgação de informações na negociação de valores mobiliários e na aquisição de lote significativo de ações de emissão de companhia aberta, estabelece vedações e condições para a negociação de ações de companhia aberta na pendência de fato relevante não divulgado ao mercado. Rio de Janeiro: CVM, 2002.

CVM. Comissão de Valores Imobiliários. Instrução CVM 361 de 5 de março de 2002. Dispõe sobre o procedimento aplicável às ofertas públicas de aquisição de ações de companhia aberta, o registro das ofertas públicas de aquisição de ações para cancelamento de registro de companhia aberta, por aumento de participação de acionista controlador, por alienação de controle de companhia aberta, para aquisição de controle de companhia aberta quando envolver permuta por valores mobiliários, e de permuta por valores mobiliários. Rio de Janeiro: CVM, 2002.

DEUTSCH, A.. A Governança Corporativa no Brasil. Salvador: 2014.

FACHIN, O.. Fundamentos de metodologia. 4 ed. São Paulo: Saraiva, 2003.

IBGC. Instituto Brasileiro de Governança Corporativa. Código Brasileiro de Governança Corporativa: Companhias Abertas. São Paulo: IBGC, 2016.

IBGC. Instituto Brasileiro de Governança Corporativa. Código das melhores práticas de governança corporativa. São Paulo: IBGC, 2009.

IBGC. Instituto Brasileiro de Governança Corporativa. Código das Melhores Práticas de Governança Corporativa. São Paulo: IBGC, 2010.
IBGC. Instituto Brasileiro de Governança Corporativa. Código das Melhores Práticas de Governança Corporativa. São Paulo: IBGC, 2007.

IBGC. Instituto Brasileiro de Governança Corporativa. Guia de Orientação para Planejamento de Sucessão, Avaliação e Remuneração de Conselho de Administração e DiretorPresidente. São Paulo: IBGC, 2011

IBGC. Instituto Brasileiro de Governança Corporativa. Perfil dos Conselhos de Administração. São Paulo: IBGC 2016.

KASHIO, G. M.. O Conselho de Administração como Mecanismo de Governança Corporativa. Recife: Universidade Presbiteriana Mackenzie, 2007.

LANZ, T. M.. Os Conselhos: Consultivo, de Administração e Familiar: Uma visão interdisciplinar. In: PRADO, R. N.. Empresas Familiares: uma visão interdisciplinar. São Paulo: Noeses, 2015. p.231-232.

LODI, J. B.. Governança corporativa: O governo da empresa e o conselho de administração. 3 ed. Rio de Janeiro: Campus, 2000.

NALDER, D. A.. Building better board. Harvard Business Review Boston, v.82, n.5, 2004.

OLIVEIRA, D. L.. Deveres e responsabilidade dos Administradores da S/A. Dissertação (Mestrado em Direito Empresarial) - Pontifícia Universidade Católica, São Paulo, 2008.

OLIVEIRA, D. P. R.. Governança Corporativa na prática. São Paulo: Atlas, 2006

OLIVEIRA, S. L.. Metodologia científica aplicada ao direito. São Paulo: Pioneira Thomson Learning, 2002.

PAIVA, E.. OPA: ofertas públicas de aquisição de ações. Rio de Janeiro: 2014

PRADO, R. N.. Empresas Familiares: uma visão interdisciplinar. São Paulo: Noeses, 2015.

PRADO, R. N.. Oferta Pública de Ações Obrigatórias nas S.A.: Tag Along. São Paulo, Quartier Latin, 2005.

RODRIGUES, C. A. P.. A Importância de Conselhos na Governança Corporativa. São Paulo: Endeavor Brasil, 2012.

SILVA, E. C.. Governança Corporativa nas Empresas: Guia prático de orientação para acionistas, investidores, conselheiros de administração e fiscal, auditores, executivos, gestores, analistas de mercado e pesquisadores. 4 ed. São Paulo: Atlas, 2016

YAZBEK, P.. O que acontece ao acionista quando a empresa fecha o capital. São Paulo: 2013.

A CBPC - Companhia Brasileira de Produção Científica (CNPJ: 11.221.422/0001-03) detém os direitos materiais desta publicação. Os direitos referem-se à publicação do trabalho em qualquer parte do mundo, incluindo os direitos às renovações, expansões e disseminaç̃̃es da contribuição, bem como outros direitos subsidiários. Todos os trabalhos publicados eletronicamente poderão posteriormente ser publicados em coletâneas impressas sob coordenação da Sustenere Publishing, da Companhia Brasileira de Produção Científica e seus parceiros autorizados. Os (as) autores (as) preservam os direitos autorais, mas não têm permissão para a publicação da contribuição em outro meio, impresso ou digital, em português ou em tradução. 